\title{
School Smoking Policy Characteristics and Individual Perceptions of the School Tobacco Context: Are They Linked to Students' Smoking Status?
}

\author{
Catherine M. Sabiston - Chris Y. Lovato - Rashid Ahmed • \\ Allison W. Pullman · Valerie Hadd · H. Sharon Campbell · \\ Candace Nykiforuk $\cdot$ K. Stephen Brown
}

Received: 23 January 2009/ Accepted: 25 May 2009/Published online: 7 June 2009

(C) The Author(s) 2009. This article is published with open access at Springerlink.com

\begin{abstract}
The purpose of this study was to explore individual- and school-level policy characteristics on student smoking behavior using an ecological perspective. Participants were 24,213 (51\% female) Grade $10-11$ students from 81 schools in five Canadian provinces. Data were collected using student self-report surveys, written policies collected from schools, interviews with school administrators, and school property observations to assess multiple dimensions of the school tobacco policy. The multi-level modeling results revealed that the school a student attended was associated with his/her smoking behavior. Individuallevel variables that were associated with student smoking included lower school connectedness, a greater number of family and friends who smoked, higher perceptions of student smoking prevalence, lower perceptions of student smoking frequency, and stronger perceptions of the school tobacco context. School-level variables associated with
\end{abstract}

\section{M. Sabiston}

Department of Kinesiology and Physical Education,

McGill University, Montreal, QC, Canada

C. Y. Lovato $(\varangle) \cdot$ A. W. Pullman

School of Population and Public Health, University of British

Columbia, Vancouver, BC, Canada

e-mail: chris.lovato@ubc.ca

R. Ahmed · H. S. Campbell · K. S. Brown

Department of Statistics and Actuarial Science, University

of Waterloo, Waterloo, ON, Canada

V. Hadd

School of Human Kinetics, University of British Columbia,

Vancouver, BC, Canada

C. Nykiforuk

School of Public Health, University of Alberta, Edmonton,

$\mathrm{AB}$, Canada student smoking included weaker policy intention indicating prohibition and assistance to overcome tobacco addiction, weaker policy implementation involving strategies for enforcement, and a higher number of students smoking on school property. These findings suggest that the school environment is important to tobacco control strategies, and that various policy dimensions have unique relationships to student smoking. School tobacco policies should be part of a comprehensive approach to adolescent tobacco use.

Keywords Adolescents - Smoking - Tobacco use · School policies $\cdot$ School environment

\section{Introduction}

Tobacco use is currently the leading cause of preventable death worldwide (World Health Organization 2006), and is widely acknowledged as a critical public health concern. Typically, smoking initiation occurs during adolescence, a time when many youth experiment with addictive substances. Tobacco use in adolescence is associated with a range of health-compromising behaviors and increased risk factors for health problems in adulthood (American Lung Association 2003). It is estimated that $90 \%$ of current smokers take up smoking before the age of 21 (American Lung Association 2003). Despite a number of tobacco control strategies aimed at preventing adolescent smoking, approximately $48 \%$ of Canadian youth experiment with tobacco products (Health Canada 2008). In order to reduce the burden of disease caused by tobacco use, efforts should be placed on understanding the complex environment in which adolescents' smoking initiation and maintenance occurs. 
Comparable to other developed countries, Canadian legislation prohibits the sale of tobacco products to minors, and these regulations are actively enforced. In recent years, many Canadian municipalities have restricted tobacco use in public spaces including work-places, restaurants, parks, and school grounds. In addition to government legislation, many schools have developed comprehensive tobacco control interventions that include cessation and prevention programs, and policies that ban tobacco use on school property. These comprehensive approaches have been guided by ecological frameworks in which the school context is a central dimension associated with student smoking (Aveyard et al. 2004; Flay et al. 1999; Petraitis et al. 1995). Specifically, there is evidence that school tobacco policies (Lovato et al. 2007; Moore et al. 2001; Schnohr et al. 2008; Wakefield et al. 2000), and social modeling characteristics, such as the visibility of smoking and tobacco norms at school (Leatherdale et al. 2005a, b; Maes and Lievens 2003; Moore et al. 2001; Poulin 2007; Wakefield et al. 2000), are associated with adolescents' tobacco use. There is limited evidence of the combined associations among school tobacco policies, the smoking social context, and adolescent tobacco use. Combined school approaches may help advance efforts aimed at reducing youths' smoking rates.

From an ecological perspective, the most proximal influences of individual tobacco use are related to adolescents' perceptions and beliefs (Flay et al. 1999; Petraitis et al. 1995). For example, students' perceptions of their school connectedness appear to be associated with smoking levels (Rasmussen et al. 2005). This evidence suggests that adolescents' feelings of relatedness and belonging at school may be protective of deviant behavior such as cigarette smoking. In addition to the protective effects of general connectedness, other social environment indicators are consistent risk factors of youth smoking. The number of family members and friends who smoke is strongly associated with youth tobacco use (Alexander et al. 2001; Avenevoli and Merikangas 2003), independent of the school tobacco environment. Furthermore, students' perceptions of the school smoking context, such as the presence of rules and guidelines pertaining to tobacco use, are also correlated with fewer smoking behaviors (EvansWhipp et al. 2007; Loukas et al. 2006; Lovato et al. 2007; Murnaghan et al. 2008). While many of these factors have been examined independently, there is little evidence linking social influences, school tobacco environment perceptions, and school connectedness together as interactive proximal agents of smoking behavior among youth. This ecological preposition (see Fig. 1) serves as the basis of the current study.

In addition to individual factors, a second level of influence is the school context. The importance of the

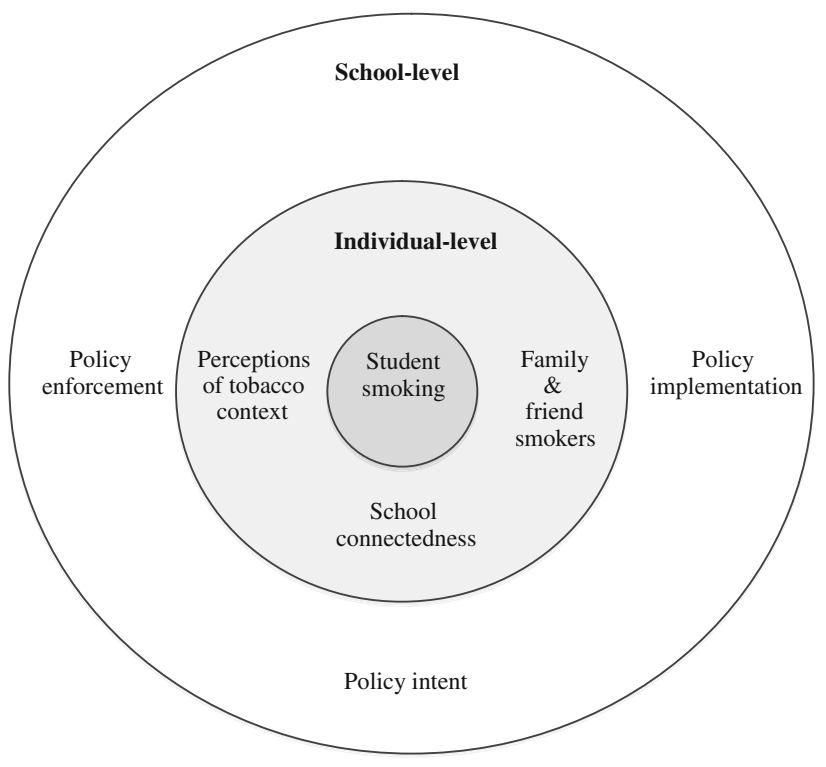

Fig. 1 The ecological perspective of student smoking behavior

school context is highlighted by the fact that youth spend much of their time at school and may subsequently be exposed to factors that increase tobacco use in that setting (Alexander et al. 2001). Schools that have smoke-free environments have lower smoking rates and less overall consumption of cigarettes than schools with minimal tobacco guidelines (Pentz et al. 1997; Wakefield et al. 2000). Unfortunately, findings of the relationship between school policies and adolescent smoking are mixed. Some research indicates a weak to moderate relationship between policies and student smoking while other studies indicate no effects (Denman et al. 2008; Barnett et al. 2007; Darling and Reeder 2003; Griesbach et al. 2002; Murnaghan et al. 2007; Northrup et al. 1998; Poulin 2007; Reitsma and Manske 2004; Wakefield et al. 2000). Further efforts are needed to better understand the ambiguity in the associations between tobacco policies and student smoking. The current study focuses on assessing multiple dimensions of school tobacco policies (see Fig. 1) to identify unique efforts that may be most effective at lower smoking rates among youth.

To date, the literature is limited in terms of understanding specific policy approaches that are most effective at curbing tobacco use among youth. In a review of school drug policies, Evans-Whipp et al. (2004) found that school policies varied substantially in their approaches and targeted enforcement. Specific to tobacco control, more comprehensive and strongly enforced policies were associated with less smoking. Part of the general ambiguity in understanding the relationship between school policies and youth smoking stems from the predominant focus on students' perceptions of policy enforcement, with little evaluation of actual school policies or policy characteristics. 
Furthermore, whereas comprehensive tobacco control policies may be most effective (Evans-Whipp et al. 2004), there have been limited efforts directed at detailing and assessing the multiple characteristics of school tobacco policies. Specifically, inter-related processes in school tobacco policy development and execution must be considered to ensure effectiveness (Trinidad et al. 2005; Willemsen and De Zwart 1999). Previous studies have focused on global measures such as the absence or presence of a policy. Policy intent (i.e., what is intended based on developed written documents), implementation (i.e., what actions are taken according to administrators), and enforcement (i.e., what is the outcome following action) should be viewed as separate yet highly dependent factors associated with adolescent smoking behavior. Previous research has often failed to make any distinction between these policy elements. This has led to inconsistencies in the way tobacco control policies are defined, measured, and evaluated, thus making it difficult to synthesize results and provide best practice advice to decision-makers.

\section{Purpose and Hypotheses}

Given the multilevel nature of these data, a preliminary aim of this study was to describe the smoking context in schools across Canada. It was hypothesized that smoking rates and policy characteristics would vary across schools. The main purpose of this study was to explore the relationships among individual factors (i.e., family and friend smoking, school connectedness, perceptions of school tobacco context), school policy characteristics (intention, implementation, and enforcement), and adolescent smoking behavior. Based on empirical and theoretical evidence, it was hypothesized that greater exposure to family and friends who smoke and lower school connectedness would be related to higher youth smoking levels. Furthermore, students reporting being at a school with more smokers, seeing smoking occurring on school grounds, and being unaware of tobacco rules and consequences would be more likely to smoke. Finally, it was hypothesized that lower levels of school policy intent, implementation, and enforcement would be associated with higher school smoking rates.

\section{Methods}

Participants and Procedures

An original cohort of 130 secondary schools with students in grades 10 and 11 was established in five Canadian provinces-British Columbia (BC), Manitoba (MB), Ontario $(\mathrm{ON})$, Quebec (QC) and Newfoundland (NL)—using a systematic probability sampling procedure. These provinces were selected for pragmatic reasons since they had established infrastructure in place to conduct data collection, had central survey research centers, represented a reasonable geographical balance, and spanned the range of 15-19 year old smoking rates (15-24\%) as reported at the time of the data collection (Health Canada 2004). Eligible schools had students in both Grades 10 and 11, were located in municipalities with a population of at least $10,000,{ }^{1}$ and were not of private, religious, or chartered nature. Eligible school districts within municipalities in $\mathrm{BC}, \mathrm{MB}$ and $\mathrm{ON}$ were grouped together based on their respective health region's smoking rate. School districts were grouped to ensure that all municipalities in the same group had the same health district and, hence, the same smoking rate. In QC, each eligible school district (with a minimum of three eligible schools) was considered a group. In NL, 13 schools were eligible to participate, and thus all schools were approached to participate in the study without being grouped.

Within the selected groups across Canada, all eligible secondary schools were identified and then selected by random number, based on the number of schools per group. With few exceptions, the first three or four randomly selected schools per group made up the sample, resulting in the following distribution by province: BC-24, MB-12, NL-12, ON-32, QC-32. Additional randomly selected schools formed a substitute list. In the event that a school refused to participate, a school was selected from the list of substitute schools. Sampling resulted in a target of 112 schools across five participating provinces. The final sample included 81 schools (72.3\% response rate) and 24,213 out of 29,492 eligible students ( $82.1 \%$ response rate). The average age of the sample was 16 years $(\mathrm{SD}=0.77)$, with $53.2 \%$ of the sample in Grade 10. Males comprised $49 \%$ of the sample. Based on the 2001 Census data, the final sampled schools were in heterogeneous municipalities that varied in terms of population (10,425-774,075 residents), average education level less than grade $9(0.68-14.74 \%)$, unemployment rate (3.80-17.80\%), median total household income $(\$ 29,654-\$ 84,682)$, and percentage of immigrants (1.2-61\%). Ethics approval outlining passive parental consent and active participant consent procedures were obtained in all participating provinces. This study was approved by the University of British Columbia Behavioural Research Ethics Board.

\footnotetext{
$\overline{1}$ The cities of Vancouver, Montreal, and Toronto and their surrounding metropolitan areas were excluded from the sample as these major cities are culturally unique and significantly larger than other Canadian municipalities; hence results could not be generalized beyond those populations.
} 
Table 1 Descriptive statistics and percentage of students reporting perceptions of the school tobacco environment (level 1 variables)

\begin{tabular}{|c|c|c|c|}
\hline & Male & Female & Total \\
\hline \multicolumn{4}{|l|}{ Dependent variable } \\
\hline Smoked in last 30 days ( $\%$ yes) & $2,450(20.55)$ & $2,883(23.46)$ & $5,333(22.03)$ \\
\hline \multicolumn{4}{|l|}{ Covariates } \\
\hline Age (mean, SD) & $15.94(0.79)$ & $15.89(0.76)$ & $15.91(0.77)$ \\
\hline \multicolumn{4}{|l|}{ School context } \\
\hline School connectedness (mean, SD) & $3.66(1.58)$ & $3.92(1.41)$ & $3.79(1.50)$ \\
\hline Number of family members who smoke (mean, SD) & $0.69(0.89)$ & $0.75(0.92)$ & $0.72(0.91)$ \\
\hline Number of friends who smoke (mean, SD) & $1.17(1.63)$ & $1.31(1.65)$ & $1.24(1.64)$ \\
\hline Student perception of school smoking prevalence (mean, SD) & $38.8(22.4)$ & $43.8(20.7)$ & $41.4(21.7)$ \\
\hline Student perception of school smoking frequency (\% yes) & $11,169(95.36)$ & $11,742(96.50)$ & $22,911(95.94)$ \\
\hline Student perceptions of school smoking context (mean, SD) & $1.52(1.08)$ & $1.56(1.06)$ & $1.54(1.07)$ \\
\hline
\end{tabular}

Data Sources and Measures

\section{Outcome Variable}

Student Smoking Student smoking behaviors were assessed during the 2003-2004 school year using the tobacco module of the School Health Action, Planning and Evaluation System (SHAPES, see www.shapes.uwaterloo. ca; Cameron et al. 2007), which is a valid and reliable, machine readable survey. For this study, smoking status was assessed by: "Did you smoke a cigarette in the last 30 days?" and "Have you ever smoked a whole cigarette?". Students who responded "yes" to having smoked at least a puff of a cigarette in the last 30 days and to having ever smoked a whole cigarette were classified as smokers, and all others were non-smokers. See Table 1 for the descriptive details of the individual level 1 variables used in the analysis.

\section{Individual-Level Variables}

The SHAPES questionnaire was used to identify individual-level correlates of smoking behavior. Individual-level correlates of youth smoking behavior were assessed as the participants' perceptions of school connectedness, number of family and friends who smoke, prevalence and frequency of student tobacco use, and the school tobacco control context.

School Connectedness Students responded to the extent that they agreed with the following items: (1) feel close to the people at this school, (2) feel that I am part of this school, (3) happy to be at this school, (4) teachers at this school treat students fairly, and (5) feel safe at this school. Responses ranged on a 4-point Likert scale from $1=$ strongly disagree to $4=$ strongly agree. These variables were then coded such that $1=$ strongly agree/agree and $0=$ strongly disagree/disagree. These five items were summed to give a final score that ranged from 0 to 5 , with higher scores representing greater perceptions of school connectedness. The internal consistency of this scale was adequate $(\alpha=0.86)$.

Number of Family Members Who Smoke Students were asked to indicate if each of their mother, father, older brothers, and older sisters smoke cigarettes. Responses were summed such that higher scores revealed more family members who smoked.

Number of Friends Who Smoke Students were asked to indicate how many of their five closest friends smoke cigarettes, with possible scores ranging from $0=$ no smoking friends to $5=$ all friends are smokers.

Prevalence of Smoking at School Students reported on the question, "How many people your age, in your school, do you think smoke cigarettes?" Responses ranged from $1=0-10 \%$ to $10=91-100 \%$ with higher scores representing higher perceived prevalence of student smokers.

Frequency of Students Smoking at School Students were asked to rate the following question on a 4-point Likert scale ranging from $1=$ false to $4=$ true: "I often see students smoking near this school". Responses were coded such that $1=$ true/usually true and $0=$ false/usually false. Higher scores represented greater perceptions of frequent student smoking on school property.

Students' Perceptions of School Tobacco Policy Enforcement Students responded to the following two questions on a 4-point Likert scale ranging from $1=$ false/I don't know to $4=$ true: "this school has a clear set of rules about smoking for students to follow" and "if students are caught breaking the smoking rules at this school, they get into 
trouble". These variables were then coded such that $1=$ true/usually true and $0=$ false/usually false/I don't know. A third item, "you can be fined for smoking on school property" was also used with responses of $1=$ true and $0=$ false/I'm not sure. These three items were combined to create a total score, and the internal consistency of this item was adequate $(\alpha=0.71)$.

\section{School-Level Variables}

School-level policy items included assessing written policies, interviewing school administrators for school policy implementation, and conducting school observations to assess policy enforcement.

School Tobacco Policy Intent (Written Policies) Tobacco policies in effect during the 2003-2004 school year were obtained from school administrators, official policy documents, or web pages to assess the tobacco context at the level of the school. In some cases the school used the district policy because they had not developed their own written policy. Two trained research assistants knowledgeable in tobacco research coded the written policies using a directed assessment coding scheme. The coders read through the school/district written policies and rated each policy components from 'poor' to 'excellent'. When rating discrepancies occurred (Kappa statistic $=0.94$ ), they were discussed until consensus was established.

The coding scheme was conceptually derived from existing rating systems (Stephens and English 2002), published school health questionnaires (Center for Chronic Disease Prevention and Health Promotion 2000; Bogden and Vega-Matos 2000), and guidelines from prominent policy researchers (Pentz et al. 1997; Stephens and English 2002). Based on these sources, seven components of tobacco policy intent were evaluated on the inclusion of the policy characteristics described below.

Developing, Overseeing, and Communication School policies were coded as $2=$ excellent if at least students and one other group (i.e., teachers/staff, parents, health professionals, or school board) were involved in the development of the policy, if there was an appointed individual or group to oversee the policy, and if the policy was communicated to the students and at least one other group (i.e., parents, teachers, visitors). A score of $1=$ acceptable was given for policies that were developed by the school and overseen and communicated by/to any of the above groups, and a score of $0=$ poor was attributed to policies that were not developed by the school (i.e., a district or provincial policy), overseen by no appointed individual or group, and had no established method of communicating the policy to others.
Purpose and Goals School policies were coded as $2=$ excellent if the policy outlined a purpose and rationale, $1=$ acceptable for the inclusion of either a purpose or a rationale, and $0=$ poor otherwise.

Prohibition School policies were coded as $2=$ excellent when students, teachers, parents, and visitors were prohibited from using cigarettes and other tobacco products, 1 = acceptable when all groups were prohibited from using cigarettes and students were prohibited from using other tobacco products, and $0=$ poor when the policy did not prohibit students and at least one other group (teachers, parents or visitors) from using cigarettes.

Strength of Enforcement Policies were coded as $2=$ excellent if verbal and written warnings were delivered to the student and parent/guardian, and sanctions were based on zero tolerance, $1=$ acceptable if written or verbal warnings were provided to students, and sanctions were based on zero tolerance, and $0=$ poor if there were no written or verbal warnings to the student, and if the sanctions were based on effect or severity of violation rather than zero tolerance.

Characteristics of Enforcement School policy scores included $2=$ excellent if more than one person/group (teachers, school administrators, by-law officers, parents, bus drivers, coaches, other school staff, or school security) was designated as ensuring policy enforcement, and the policy outlined clear enforcement strategies, $1=$ acceptable if there was at least one person designated to enforce the tobacco policy, and the policy outlined clear enforcement strategies, and $0=$ poor if there were no designated persons to ensure enforcement, and if the policy failed to outline specific enforcement strategies.

Tobacco Use Prevention Education The policy element was coded as $1=$ excellent if education was mandated and $0=$ poor if no prevention education was mandated.

Assistance to Overcome Tobacco Addictions School policies were assessed as $2=$ excellent if access to cessation programs was provided to students and other persons (at least one of staff, parents/guardians, and community members), 1 = acceptable if the policy outlined the provision or access to cessation programs for students, and $0=$ poor if cessation programs were not provided or referred to for students.

School Tobacco Policy Implementation Policy implementation was assessed using a structured interview protocol with the school administrator (the individual who was identified as the most knowledgeable on tobacco policy). A 
trained interviewer conducted the implementation survey on the same day as the student survey. The interview questions assessed the multiple dimensions of tobacco policies described in the previous section, with the additional dimensions of consistency of enforcement and the length of time the school policy had been in effect. Consistency of enforcement was coded as $2=$ excellent if both the school district and the school enforced the policy at least sometimes, $1=$ acceptable if either the school district or the school enforced the policy at least sometimes and $0=$ poor if the school district never or rarely enforced the policy, and the school never or rarely enforced the policy. The length of time the school policy had been in effect was entered in the model as a continuous variable.

To obtain a score on the policy implementation dimensions, administrator responses were coded using the same protocol and scoring system described for the written school policies. In this way, we used consistent protocols to measure and analyze policy intent and implementation. The internal consistency of this scale was adequate $(\alpha=0.66)$ since the scale was not necessarily developed to assess a global policy implementation score.

School Policy Enforcement As a proxy measure for policy enforcement, a field observation was conducted at each school in the sample to assess the visibility of smoking on or near school property. The observations were conducted between 11:30 a.m. and 1:30 p.m. on the same day that student surveys were completed. The observation involved two data collectors who independently identified the number of cigarette butts and number of smokers on the school property and the school periphery. The average of the two data collector assessments was calculated as the final score given the high consistency in coding $($ Kappa $=0.84)$.

\section{Data Analysis}

Prior to the main analyses, the validity of the instruments used to code the policies was assessed. Nine completed surveys (including both policy intent and implementation) were randomly selected and given to six tobacco policy experts. The experts rank-ordered each of the policy subscales by strength of intent and implementation, and provided rationale for their decisions. This rank ordering was compared to the strength of scores generated from the developed rating system. Consistent ratings were observed for 13 out of the $15(86.7 \%)$ policy intent and implementation subscale scores.

For the main analysis, a multilevel logistic regression model was developed to determine the strength of the hypothesized relationships between social smoking indicators, school policy characteristics and student smoking behavior. The model was specified as follows: let $Y_{j}=$ $\left(y_{j 1}, y_{j 2}, \ldots, y_{j n_{j}}\right)^{T}, x_{i j}$ be a p-vector of covariates (age and sex) associated with the $i$ th subject within the $j$ th school, $n_{j}$ be the number of students within the $j$ th school, $p_{i j}$ be the probability of observing a successful event (smoking) and $\beta$ be a p-vector of the regression coefficients.

The level 1 information (individual variables) was specified such that $y_{i j}=\pi_{i j}+\varepsilon$, where $\pi_{i j}=\log i t\left(p_{i j}\right)=$ $\log \left(\frac{p_{i j}}{1-p_{i j}}\right)=\beta_{0 j}+\beta_{p} x_{p i j}$.

At the second level (school variables), regression equations were formulated for the random intercept, $\beta_{0 j}=\beta_{0}+\mu_{0 j}$.

The multilevel model was obtained by substituting

$\pi_{i j}=\beta_{0}+\beta_{p} x_{p i j}+\mu_{0 j}$

$\pi_{i j}=\frac{\exp \left(\beta_{0 j}+\beta_{p} x_{p i j}\right)}{1+\exp \left(\beta_{0 j}+\beta_{p} x_{p i j}\right)}$

where $x_{i j}$ defined as $(p \times 1)$ vector of covariates, $E(\varepsilon)=0$, $V(\varepsilon)=\sigma^{2}=p_{i j}\left(1-p_{i j}\right)$ and $\mu_{o j} \sim N\left(0, \sigma_{\mu 0}^{2}\right)$.

A restricted pseudo-likelihood algorithm was used for estimation and a generalized Chi-Square statistic was used to measure the variability of the observations about the mean model. The statistical significance of the estimated parameters was tested using Wald statistics and is reported using the $F$-test. The Wald test was also used as an indicator of the significance of variance partition coefficient (VPC), which explained the proportion of total residual variance attributed to level 2. The Snijders and Bosker (1999) method was used to compute the VPC. All preliminary analyses were completed using the SAS software package and the robustness of results were verified using bootstrapping and Markov Chain Monte Carlo (MCMC) alternate methods of estimation within MLWIN multilevel software.

\section{Results}

\section{Descriptive Analyses}

At the individual level, approximately $22 \%$ of the students were classified as smokers (see Table 1). Spearman correlation coefficients among individual-level variables revealed low-to-moderate interrelations (see Table 2). All individual-level variables were significantly $(p<0.05)$ correlated with smoking behavior.

School smoking rates ranged from 10 to $38 \%$ across the sampled schools. School policy scores varied across schools, and seven schools had no school written policy. In these cases, the district policy had been adopted by the school and was coded for the analysis. Overall, school 
Table 2 Spearman correlation coefficients for individual level variables

\begin{tabular}{|c|c|c|c|c|c|c|}
\hline & 1. & 2. & 3. & 4. & 5. & 6. \\
\hline 1. School connectedness & - & & & & & \\
\hline 2. Family members who smoke & $-0.02 *$ & - & & & & \\
\hline 3. Friends who smoke & $-0.12 *$ & $0.33 *$ & - & & & \\
\hline 4. Student perceptions of school smoking prevalence & $-0.17^{*}$ & $0.06^{*}$ & $0.27 *$ & - & & \\
\hline 5. Student perceptions of school smoking frequency & $-0.02 *$ & $-0.03 *$ & $-0.02 *$ & $0.06^{*}$ & - & \\
\hline 6. Student perceptions of school tobacco context & $0.12 *$ & 0.01 & $0.14 *$ & $0.05 *$ & $0.03 *$ & - \\
\hline 7. Student smoking & $-0.07 *$ & $0.08^{*}$ & $0.58 *$ & $0.15^{*}$ & $-0.02 *$ & $0.09^{*}$ \\
\hline
\end{tabular}

$* p<0.01$

tobacco policies were considered weak based on the low prevalence of acceptable and excellent scores calculated for both the policy intention and implementation subscales (see Table 3).

Based on the policy enforcement data, students were observed smoking on $61 \%(n=50)$ and $54 \%(n=44)$ of the school grounds and periphery, respectively. Student smoking was not detected at five schools due to limited accessibility or visibility of the school property. These schools were not included in the main analysis. There were no significant differences in the prevalence of smoking- or policy-related scores for these schools compared to those remaining in the analysis. Furthermore, cigarette butts were observed on $90.1 \%(n=73)$ of the school grounds, with the inability to count cigarette butts on the remaining eight school grounds due to weather (i.e., snow covering the ground) or location (i.e., the inability of the observers to unobtrusively access the school property or the constant presence of students in the area). Given the lack of variability in the presence of cigarette butts on school property, and difficulty in assessing cigarette butts for 8 schools, this variable was not entered in the multilevel model.

Spearman correlation coefficients among school-level variables revealed significant $(p<0.05)$ low to moderate inter-relationships among several intent and implementation subscales (see Table 4). The dimensions of "Purpose and Goals" and "Strength of Enforcement" for both policy intent and implementation showed moderate-to-high intercorrelations with several policy variables, and, for this reason, were not included in the final model.

\section{Multilevel Analysis}

The null model demonstrated significant between-school random variation (see Table 5), suggesting that the school a student attended impacted the odds of being a smoker. All individual-level variables were significant correlates of smoking behavior in both Models 2 (Level-1 variables only) and 3 (Level-1 and -2 variables included), and demonstrated similar effect sizes and direction of effects in
Table 3 Means and standard deviations (SD) for school policy intention and implementation subscales (level 2 variables)

\begin{tabular}{|c|c|c|}
\hline & \multicolumn{2}{|c|}{$\begin{array}{l}\text { Acceptable or excellent } \\
\text { rating }(\%)\end{array}$} \\
\hline & Intent & Implementation \\
\hline \multicolumn{3}{|c|}{ Developing, overseeing \& communication } \\
\hline Poor & 95.1 & 13.6 \\
\hline Acceptable & 4.9 & 61.7 \\
\hline Excellent & 0.0 & 24.7 \\
\hline \multicolumn{3}{|l|}{ Purpose and goals } \\
\hline Poor & 46.9 & 58.0 \\
\hline Acceptable & 28.4 & 22.2 \\
\hline Excellent & 24.7 & 19.8 \\
\hline \multicolumn{3}{|l|}{ Prohibition } \\
\hline Poor & 61.7 & 14.8 \\
\hline Acceptable & 35.8 & 75.3 \\
\hline Excellent & 2.5 & 9.9 \\
\hline \multicolumn{3}{|l|}{ Strength of enforcement } \\
\hline Poor & 92.7 & 17.3 \\
\hline Acceptable & 6.2 & 60.5 \\
\hline Excellent & 1.1 & 22.2 \\
\hline \multicolumn{3}{|l|}{ Consistency of enforcement } \\
\hline Poor & - & 29.6 \\
\hline Acceptable & - & 39.5 \\
\hline Excellent & - & 30.9 \\
\hline \multicolumn{3}{|l|}{ Characteristics of enforcement } \\
\hline Poor & 64.2 & 33.3 \\
\hline Acceptable & 23.5 & 46.9 \\
\hline Excellent & 12.3 & 19.8 \\
\hline \multicolumn{3}{|l|}{ Tobacco use prevention education } \\
\hline Poor & 93.8 & 85.2 \\
\hline Excellent & 6.2 & 14.8 \\
\hline \multicolumn{3}{|c|}{ Assistance to overcome tobacco addictions } \\
\hline Poor & 92.6 & 30.9 \\
\hline Acceptable & 3.7 & 39.5 \\
\hline Excellent & 3.7 & 29.6 \\
\hline $\begin{array}{l}\text { Length of time the policy had been } \\
\text { in effect, in years (mean, SD) }\end{array}$ & - & $8.87(6.10)$ \\
\hline
\end{tabular}




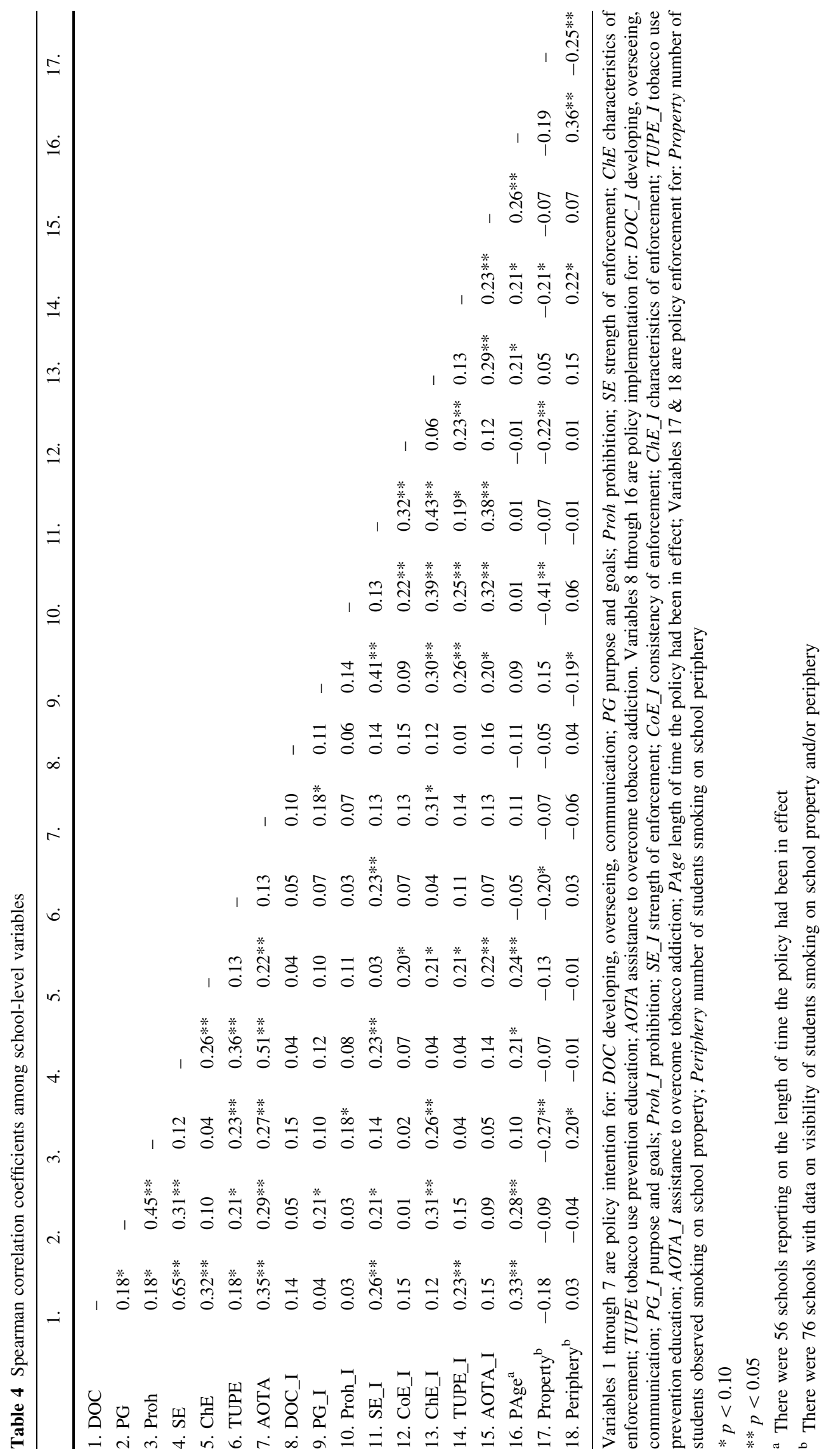


Table 5 Multilevel analysis of student perceptions of policy enforcement and smoking on the school property and periphery, school policy intention and implementation, and visibility of student smoking behavior related to the odds of being a smoker versus a non-smoker

\begin{tabular}{|c|c|c|c|c|c|}
\hline \multirow[t]{2}{*}{ Parameter } & \multirow[t]{2}{*}{ Model 1 (null) } & \multicolumn{2}{|l|}{ Model 2} & \multicolumn{2}{|l|}{ Model 3} \\
\hline & & Estimate (SE) & $\begin{array}{l}\text { Odds ratio } \\
(95 \% \mathrm{CI})\end{array}$ & Estimate (SE) & $\begin{array}{l}\text { Odds ratio } \\
(95 \% \mathrm{CI})\end{array}$ \\
\hline \multicolumn{6}{|l|}{ Level 1 (Individual level variables) } \\
\hline \multicolumn{6}{|l|}{ Covariates } \\
\hline Age & & $0.15(0.03)^{* *}$ & $1.16(1.10,1.22)$ & $0.13(0.03)^{* *}$ & $1.14(1.07,1.22)$ \\
\hline Sex (male) & & $-0.14(0.04)^{* *}$ & $0.87(0.80,0.94)$ & $-0.22(0.05)^{* *}$ & $0.80(0.72,0.89)$ \\
\hline \multicolumn{6}{|l|}{ Smoking context } \\
\hline School connectedness & & $-0.09(0.01)^{* *}$ & $0.91(0.89,0.93)$ & $-0.11(0.02)^{* *}$ & $0.90(0.87,0.93)$ \\
\hline Family members who smoke & & $0.25(0.03)^{* *}$ & $1.29(1.22,1.36)$ & $0.29(0.03)^{* *}$ & $1.34(1.27,1.41)$ \\
\hline Friends who smoke & & $0.81(0.01)^{* *}$ & $2.24(2.19,2.30)$ & $0.81(0.016)^{* *}$ & $2.26(2.19,2.33)$ \\
\hline Perceptions of student smoking prevalence & & $0.03(0.01)^{* *}$ & $1.03(1.01,1.05)$ & $0.03(0.01)^{* *}$ & $1.04(1.01,1.06)$ \\
\hline Perceptions of student smoking frequency & & $-0.21(0.10)^{* *}$ & $0.81(0.66,0.99)$ & $-0.26(0.13)^{* *}$ & $0.77(0.60,0.98)$ \\
\hline Student perceptions of school tobacco context & & $0.17(0.02)^{* *}$ & $1.19(1.14,1.24)$ & $0.23(0.03) * *$ & $1.26(1.20,1.33)$ \\
\hline \multicolumn{6}{|l|}{ Level 2 (School-level variables) } \\
\hline \multicolumn{6}{|l|}{ Policy intent } \\
\hline Developing, overseeing, \& communication & & & & $-0.05(0.16)$ & $0.95(0.70,1.29)$ \\
\hline Purpose and goals & & & & - & - \\
\hline Prohibition & & & & $-0.19(0.07)^{* *}$ & $0.83(0.72,0.95)$ \\
\hline Strength of enforcement & & & & - & - \\
\hline Characteristics of enforcement & & & & $0.03(0.050)$ & $1.03(0.93,1.13)$ \\
\hline Tobacco use prevention education & & & & $0.21(0.12)$ & $1.23(0.96,1.57)$ \\
\hline Assistance to overcome tobacco addictions & & & & $-0.29(0.11)^{* *}$ & $0.74(0.60,0.92)$ \\
\hline \multicolumn{6}{|l|}{ Policy implementation } \\
\hline Developing, overseeing, \& communication & & & & $0.02(0.07)$ & $1.02(0.89,1.16)$ \\
\hline Purpose and goals & & & & - & - \\
\hline Prohibition & & & & $0.07(0.09)$ & $1.07(0.89,1.28)$ \\
\hline Strength of enforcement & & & & - & - \\
\hline Characteristics of enforcement & & & & $-0.10(0.052)^{* *}$ & $0.90(0.81,1.00)$ \\
\hline Consistency of enforcement & & & & $0.07(0.05)$ & $1.07(0.98,1.17)$ \\
\hline Tobacco use prevention education & & & & $0.10(0.10)$ & $1.10(0.90,1.35)$ \\
\hline Assistance to overcome tobacco addictions & & & & $0.03(0.05)$ & $1.03(0.94,1.12)$ \\
\hline Length of time the policy had been in effect & & & & $0.01(0.01)^{*}$ & $1.01(1.00,1.03)$ \\
\hline \multicolumn{6}{|l|}{ Policy enforcement } \\
\hline Students smoking on school property & & & & $0.19(0.05)^{* *}$ & $1.20(1.09,1.32)$ \\
\hline Students smoking on school periphery & & & & $0.03(0.05)$ & $1.03(0.93,1.14)$ \\
\hline \multicolumn{6}{|l|}{ Overall model } \\
\hline$\Sigma_{\mu 0}^{2}$ & $0.14(0.026)$ & $0.11(0.022)$ & & $0.07(0.026)$ & \\
\hline-2 Res log pseudo-likelihood & $113,108.5$ & $118,197.0$ & & $752,11.23$ & \\
\hline $\mathrm{VPC}(\%)$ & 4.21 & 3.31 & & 2.02 & \\
\hline
\end{tabular}

* Significant at $p<0.10$

** Significant at $p<0.05$

both models (see Table 5). Based on the likelihood ratio test, Model 3 is the best-fitting model. Many individualand school-level variables were significantly related to the likelihood of being a smoker versus a non-smoker, after adjusting for gender and age.
Students who reported higher numbers of social influences who smoke were more likely to be smokers (number of family members who smoke, $\mathrm{OR}=1.34,95 \%$ $\mathrm{CI}=1.27-1.41$; number of friends who smoke, $\mathrm{OR}=$ 2.26, $95 \% \quad \mathrm{CI}=2.19-2.33)$. Perceptions of school 
connectedness were protective of smoking behavior $(\mathrm{OR}=0.90,95 \% \mathrm{CI}=0.87-0.93)$. Adolescents were more likely to be smokers when they perceived a greater prevalence of smokers $(\mathrm{OR}=1.04,95 \% \mathrm{CI}=1.01-1.06)$ and less frequent smoking $(\mathrm{OR}=0.77,95 \% \mathrm{CI}=0.60-0.98)$ at their school. Students' perceptions of school tobacco context were associated with a greater likelihood of smoking $(\mathrm{OR}=$ $1.26,95 \% \mathrm{CI}=1.20-1.33$ ).

Only four of the 11 intention, implementation, and enforcement school-level variables were significant at $p<0.05$. A student who was a smoker was less likely to come from a school that had stronger policy intent for assistance to overcome addictions ( $\mathrm{OR}=0.74,95 \% \mathrm{CI}=$ 0.60-0.92), and also less likely to come from a school that had stronger prohibition $(\mathrm{OR}=0.83,95 \% \mathrm{CI}=$ 0.72-0.95), than a non-smoker. Policy implementation subscales for characteristics of enforcement were protective of tobacco use $(\mathrm{OR}=0.90,95 \% \mathrm{CI}=0.81-1.00)$. Furthermore, the presence of students smoking on school property $(\mathrm{OR}=1.20,95 \% \mathrm{CI}=1.09-1.32)$ increased the odds of a student being a smoker.

\section{Discussion}

The purpose of this study was to examine adolescents' perceptions of the school tobacco environment and school policy characteristics as correlates of student smoking status. The findings confirm existing evidence and the hypothesis that smoking rates vary across schools (Aveyard et al. 2004; Leatherdale et al. 2005a, b, c; Moore et al. 2001; Murray et al. 2002), which highlights the importance of examining between-school variation in smoking prevalence using multilevel modeling. Since cigarette butts were observed on $90.1 \%$ of school grounds, we can conclude that smoking occurs at the majority of schools in the current study. Therefore, the school context is an important target for understanding and subsequently targeting youth smoking behavior.

The current individual-level findings support the main study hypotheses. First, these findings confirm well-documented evidence that students are more likely to smoke if they have family members and/or friends who smoke (Alexander et al. 2001; Aloise-Young et al. 1994; Avenevoli and Merikangas 2003; Duncan et al. 1995; Kobus 2003; Urberg et al. 1997). These social influences should remain a priority in the tobacco control efforts aimed at reducing youth smoking. Second, consistent with the majority of research in this area (Evans-Whipp et al. 2007; Hunter et al. 1982; Leatherdale and Manske 2005; Loukas et al. 2006; Otten et al. 2009), students were more likely to smoke if they perceived more student smokers at their school. Tobacco control efforts need to be directed at both student perceptions of smoking rates (Reid et al. 2008) as well as reducing the visibility of student smokers at school. Finally, school connectedness was protective of smoking behavior. There is empirical evidence supporting this finding with similar constructs, such as attachment (Dornbusch et al. 2001), culture (Bisset et al. 2007), students' sense of community (Battistich and Hom 1997), and connectedness (Rasmussen et al. 2005). Based on social control theory (Hirschi 1998), the adolescent's social bond to the school is likely protective of deviant acts such as tobacco use because he or she feels compelled, or committed, to adhere to appropriate behavioral standards. Furthermore, adolescents with low or weak perceptions of school connectedness would be uncommitted to the school anti-smoking values and more likely to become attached to substance-using peers (Petraitis et al. 1995). For example, Bond et al. (2007) found low school connectedness assessed in early adolescence was associated with an elevated risk for regular smoking in later adolescence. Whereas more longitudinal studies of this nature are warranted, the growing evidence suggests school connectedness is an important factor in understanding adolescents' tobacco use. Schools may consider implementing interventions to increase cohesion and positive social dynamics among students.

Inconsistent with our hypothesis, individuals who frequently observed other students smoking were less likely to smoke themselves. There are few reports distinguishing perceived prevalence and frequency of smoking at school, and our findings suggest that understanding this distinction warrants further investigation. It may be that smokers perceive there to be less frequent smoking as a result of stronger tobacco policies that restrict the location of use (but not necessarily the number of adolescents using tobacco). This may suggest that policies have impacted the frequency of smoking that takes place during the school day. Longitudinal data are needed to examine these changes over time. Furthermore, the interaction of prevalence and frequency of smoking at school should be examined to more completely understand the effects on student tobacco use. Drawing from the prevalence literature, it may be important to look at the different stages of smoking development (i.e., never, trial, non-daily, regular, quitters), the prevalence of tobacco use across different stages of smoking, and the frequency of use among those at different stages of smoking rather than to focus only on regular smokers (Reid et al. 2008; Sussman 1989). More research is needed to distinguish prevalence and frequency of tobacco use at school, and the unique antecedents and outcomes of these individual-level smoking variables.

Although contrary to the hypothesis, the finding that adolescents who smoke were more likely to perceive strong policy enforcement at school is consistent with 
existing research using Canadian data (Leatherdale et al. 2005a, b; Murnaghan et al. 2007, 2008). Recent findings suggest that students' awareness of tobacco policies and programs is different for occasional smokers compared to regular or non-smokers (Murnaghan et al. 2008). Also, characteristics of smoking risk, such as having family and friends who smoke, exacerbate perceptions of tobacco policy enforcement and youths' subsequent smoking behavior (Murnaghan et al. 2007, 2008). The current study did not focus on the link between smoking behavior and stage of smoking development or interactions between atrisk characteristics and perceptions of tobacco control enforcement at the school. It is important to follow the longitudinal relationships between perceptions of tobacco policy enforcement and smoking behavior. It is possible that smokers who perceive strong policy enforcement will quit smoking over time. A limitation of many existing research findings is the predominant focus on student perceptions of school tobacco policies. Our study advances this literature in that we have collected and assessed data on policy intent, implementation, and enforcement and do not depend solely on student perceptions of policy action at their school.

The relationship between policy characteristics and student smoking partially supported our hypotheses. The odds of being a smoker were reduced in schools with stronger policy intent for prohibition and assistance to overcome tobacco addiction, and more comprehensive characteristics of enforcement for policy implementation. Thus, it appears that school policies that prohibit smoking among students, teachers, and visitors alike, and also provide cessation programs for all these groups, are more likely to be associated with lower smoking rates. While research efforts have not often focused on the multiple facets of tobacco policies, there is evidence that teacher smoking increases the odds of students' smoking behaviors (Poulsen et al. 2002). It is therefore not surprising that policy efforts should extend beyond the student. Furthermore, school policies that are enforced by more than one individual and have clearly outlined enforcement strategies are associated with less smoking by students. The current study is one of the first to examine actual school tobacco policies, and these results suggest that future research should consider the multiple dimensions of the intent of policies and their implementation when exploring youths' smoking behaviors.

Since other studies have reported a weak effect of policies on youth smoking prevalence (Darling et al. 2006; Griesbach et al. 2002; Lovato et al. 2007), it is important to consider that school policies limit and govern the location and time of tobacco use, but they do not prohibit students from smoking in general (Lovato et al. 2007). Second, actions used to deal with students who violate smoking policy restrictions (i.e., fines, detentions) may be more important than the presence of health and drug policies (Hamilton et al. 2003). As such, measures assessing the number of fines or detentions resulting from tobacco-related violations may be beneficial. Third, policies alone may fall short of changing behaviors-especially during adolescence when exploration of deviant behaviors, such as tobacco use, may be a natural course of development (Igra and Irwin 1996). All of these factors need to be considered in future research studies aiming to address the issue of youth tobacco use.

Using a combination of ecological models and theories of adolescent development, we may be able to better inform research and practice focused on linking school tobacco policies and students' tobacco use. There is evidence that comprehensive community and school approaches to control adolescents' tobacco use (Pierce et al. 2005), as well as alcohol (Perry et al. 1996, 2002), and drugs (Evans-Whipp et al. 2007; Furr-Holden et al. 2004; Willemsen and De Zwart 1999) may provide more longterm success at reducing substance use than policies alone. Based on the findings of Perry et al. (2002), it may also be important to consistently maintain such efforts throughout adolescence. In the current study, policies that had been in effect for a longer period of time were related to increased odds of being a smoker. Tobacco policies should therefore be revised and adapted as the school and community landscapes change over time.

Finally, in addition to studying the association between school tobacco policy intent and implementation on student smoking behavior, the current study also examined policy enforcement indicators. The observed relationship between smoking status and policy enforcement (i.e., visibility of smoking on school property) is consistent with our hypothesis based on theoretical perspectives of observational learning (Bandura 1997) and empirical evidence (Leatherdale et al. 2005c). Enforcing a school tobacco-free environment reduces adolescent smoking rates (Pinilla et al. 2002), yet imposes demands on staff and teachers that are difficult to uphold (Ashley et al. 1998). Furthermore, there is contradictory evidence that regulated smoking locations on school property (i.e., smoking pits) are effective at reducing smoking rates among youth (Sussman 1989; Ashley et al. 1998; Baillie et al. 2008; Kumar et al. 2005; McBride 2006). Sussman (1989) suggests that these designated areas legitimize smoking. However, the threat that students will leave school property to smoke and disrupt community environments at large (McBride 2006) has been impetus to seeking designated areas for students to smoke on school property (Ashley et al. 1998). Nonetheless, the most effective and practical options for reducing 
the visibility of school smoking have not yet been identified. Based on the findings presented here, these options should be a priority for comprehensive approaches to school-based tobacco control programs.

There are a number of limitations associated with this study. Results are based on cross-sectional data, and therefore do not take into account the effects of time on the impact of school policies. All student level information, and some information regarding school policies, was based on self-report; therefore the validity of the responses cannot be guaranteed. Where possible, effort has been made to use measures that have been shown to have a high reliability in terms of self-reporting. Results from multi-level analyses are modest and may reflect the generally weak level of policies across the schools in our sample. Additionally, the observation of smoking at school was limited to 1 day of the year, and one time of day. While this is not representative of seasonal changes and daily fluctuations in smoking at the school, the economic and logical feasibility of conducting more than one observation in over 80 schools across five Canadian provinces precluded further assessment. There may be stronger measures of policy enforcement, such as the number of suspensions and fines in the current school year. Finally, this study has contributed to development of school policy measurement; however, further work in this area is needed. Future research should continue to develop and test the intent and implementation measures as new school policy development and implementation emerges.

In spite of these limitations, this study makes important contributions to understanding adolescent smoking. Not only are consistent relationships noted in terms of the individual characteristics that are associated with smoking behaviour but also important school tobacco policy characteristics are highlighted. Many studies do not decipher specific policy intent, implementation, and enforcement elements, and school policies are not often evaluated. The findings also suggest that the school context is an important factor in understanding and subsequently targeting efforts aimed at reducing youths' smoking behaviors.

Acknowledgments We wish to thank the data coordinators in the five provinces represented in this study. Above all, we thank the high school administrators and students who completed the surveys. This research was supported by a Canadian Institutes of Health Research (CIHR) grant \#62748.

Conflicts of Interest Statement The authors declare that they have no conflict of interest.

Open Access This article is distributed under the terms of the Creative Commons Attribution Noncommercial License which permits any noncommercial use, distribution, and reproduction in any medium, provided the original author(s) and source are credited.

\section{References}

Alexander, C., Piazza, M., Mekos, D., \& Valente, T. (2001). Peers, schools, and adolescent cigarette smoking. Journal of Adolescent Health, 29, 22-30.

Aloise-Young, P. A., Graham, J. W., \& Hansen, W. B. (1994). Peer influence on smoking initiation during early adolescence: A comparison of group members and group outsiders. Journal of Applied Psychology, 79, 281-287.

American Lung Association. (2003). Adolescent smoking statistics. Retrieved April 29, 2009, from http://www.lungusa.org/site/ c.dvLUK9O0E/b.39868/k.AFBF/Adolescent_Smoking_Statistics. htm.

Ashley, M. J., Northrup, D. A., \& Ferrence, R. (1998). The Ontario ban on smoking on school property: Issues and challenges in enforcement. Canaidan Journal of Public Health, 89, 229-232.

Avenevoli, S., \& Merikangas, K. R. (2003). Familial influences on adolescent smoking. Addiction, 98(Suppl 1), 1-20.

Aveyard, P., Markham, W. A., \& Cheng, K. K. (2004). A methodological and substantive review of the evidence that schools cause pupils to smoke. Social Science \& Medicine, 58, 2253-2265.

Baillie, L. E., Lovato, C. Y., Taylor, E., Rutherford, M. B., \& Smith, M. (2008). The pit and the pendulum: The impact on teen smokers of including a designated smoking area in school tobacco control policy. Health Education Research, 23, 1008-1015.

Bandura, A. (1997). The anatomy of stages of change. American Journal of Health Promotion, 12, 8-10.

Barnett, T. A., Gauvin, L., Lambert, M., O’Loughlin, J., Paradis, G., \& McGrath, J. J. (2007). The influence of school smoking policies on student tobacco use. Archives of Pediatrics \& Adolescent Medicine, 161, 842-848.

Battistich, V., \& Hom, A. (1997). The relationship between students' sense of their school as a community and their involvement in problem behaviors. American Journal of Public Health, 87, 1997-2001.

Bisset, S., Markham, W. A., \& Aveyard, P. (2007). School culture as an influencing factor on youth substance use. Journal of Epidemiology and Community Health, 61, 485-490.

Bogden, J. F., \& Vega-Matos, C. A. (2000). Fit healthy and ready to learn (part 1). Alexandria, VA: National Association of State Boards of Education.

Bond, L., Butler, H., Thomas, L., Carlin, J., Glover, S., Bowes, G., et al. (2007). Social and school connectedness in early secondary school as predictors of late teenage substance use, mental health, and academic outcomes. Journal of Adolescent Health, 40, 357.e9-357.e18.

Cameron, R., Manske, S., Brown, K. S., Jolin, M. A., Murnaghan, D., \& Lovato, C. (2007). Integrating public health policy, practice, evaluation, surveillance, and research: The school health action planning and evaluation system. American Journal of Public Health, 97, 648-654.

Center for Chronic Disease Prevention and Health Promotion. (2000). School health index for physical activity and healthy eating: A self-assessment and planning guide-tobacco modifications supplement. Atlanta, GA: National Center for Chronic Disease Prevention and Health Promotion.

Darling, H., \& Reeder, A. (2003). Smoke-free schools? Results of a secondary school smoking policies survey 2002. New Zealand Medical Journal, 116, U560.

Darling, H., Reeder, A. I., Williams, S., \& Mcgee, R. (2006). Is there a relation between school smoking policies and youth cigarette smoking knowledge and behaviors? Health Education Research, $21,108-115$. 
Denman, S., Hopkins, D., Wallbanks, C., \& Skuriat, V. (2008). The management and organisation of health promotion: A survey of school policies in Nottinghamshire. Health Education Journal, $58,165-176$.

Dornbusch, S. M., Erickson, K. G., Laird, J., \& Wong, C. A. (2001). The relation of family and school attachment to adolescent deviance in diverse groups and communitities. Journal of Adolescent Research, 16, 396-422.

Duncan, T. E., Tildesley, E., Duncan, S. C., \& Hops, H. (1995). The consistency of family and peer influences on the development of substance use in adolescence. Addiction, 90, 1647-1660.

Evans-Whipp, T., Beyers, J. M., Lloyd, S., Lafazia, A. N., Toumbourou, J. W., Arthur, M. W., et al. (2004). A review of school drug policies and their impact on youth substance use. Health Promotion International, 19, 227-234.

Evans-Whipp, T. J., Bond, L., Toumbourou, J. W., \& Catalano, R. F. (2007). School, parent, and student perspectives of school drug policies. Journal of School Health, 77, 138-146.

Flay, B. R., Petraitis, J., \& Hu, F. B. (1999). Psychosocial risk and protective factors for adolescent tobacco use. Nicotine \& Tobacco Research, 1(Suppl 1), S59-S65.

Furr-Holden, C. D., Ialongo, N. S., Anthony, J. C., Petras, H., \& Kellam, S. G. (2004). Developmentally inspired drug prevention: Middle school outcomes in a school-based randomized prevention trial. Drug and Alcohol Dependence, 73, 149-158.

Griesbach, D., Inchley, J., \& Currie, C. (2002). More than words? The status and impact of smoking policies in Scottish schools. Health Promotion International, 17, 31-41.

Hamilton, G., Cross, D., Lower, T., Resnicow, K., \& Williams, P. (2003). School policy: What helps to reduce teenage smoking? Nicotine \& Tobacco Research, 5, 507-513.

Health Canada. (2004). Canadian tobacco use monitoring survey (CTUMS) annual results, 2004. Retrieved April 29, 2009, from http://www.hc-sc.gc.ca/hl-vs/tobac-tabac/research-recherche/ stat/ctums-esutc_2004-eng.php.

Health Canada. (2008). Summary of results of the 2006-2007 youth smoking survey. Retrieved April 29, 2009, from http://www. hc-sc.gc.ca/hl-vs/tobac-tabac/research-recherche/stat/_surveysondage_2006-2007/result-eng.php.

Hirschi, T. (1998). Social bond theory. In F. T. Cullen \& R. Agnew (Eds.), Criminological theory: Past to present. Los Angeles: Roxbury.

Hunter, S. M., Baugh, J. G., Webber, L. S., Sklov, M. C., \& Berenson, G. S. (1982). Social learning effects on trial and adoption of cigarette smoking in children: The Bogalusa heart study. Preventive Medicine, 11, 29-42.

Igra, V., \& Irwin, C. E. (1996). Theories of adolescent risk-taking behavior. In R. J. DiClemente, W. B. Hansen, \& L. Ponton (Eds.), Handbook of adolescent health risk behavior. New York: Spinger.

Kobus, K. (2003). Peers and adolescent smoking. Addiction, 98(Suppl 1), 37-55.

Kumar, R., O’Malley, P. M., \& Johnston, L. D. (2005). School tobacco control policies related to students' smoking and attitudes toward smoking: National survey results, 1999-2000. Health Education \& Behavior, 32, 780-794.

Leatherdale, S. T., Brown, K. S., Cameron, R., \& McDonald, P. W. (2005a). Social modeling in the school environment, student characteristics, and smoking susceptibility: A multi-level analysis. Journal of Adolescent Health, 37, 330-336.

Leatherdale, S. T., Cameron, R., Brown, K. S., \& McDonald, P. W. (2005b). Senior student smoking at school, student characteristics, and smoking onset among junior students: A multilevel analysis. Preventive Medicine, 40, 853-859.

Leatherdale, S. T., \& Manske, S. (2005). The relationship between student smoking in the school environment and smoking onset in elementary school students. Cancer Epidemiology Biomarkers \& Prevention, 14, 1762-1765.

Leatherdale, S. T., McDonald, P. W., Cameron, R., \& Brown, K. S. (2005c). A multilevel analysis examining the relationship between social influences for smoking and smoking onset. American Journal of Health Behavior, 29, 520-530.

Loukas, A., Garcia, M. R., \& Gottlieb, N. H. (2006). Texas college students' opinions of no-smoking policies, secondhand smoke, and smoking in public places. Journal of American College Health, 55, 27-32.

Lovato, C. Y., Sabiston, C. M., Hadd, V., Nykiforuk, C. I., \& Campbell, H. S. (2007). The impact of school smoking policies and student perceptions of enforcement on school smoking prevalence and location of smoking. Health Education Research, 22, 782-793.

Maes, L., \& Lievens, J. (2003). Can the school make a difference? A multilevel analysis of adolescent risk and health behavior. Social Science \& Medicine, 56, 517-529.

McBride, M. (2006). BC school smoking policy: Recommendations for future action. Victoria, BC: Tobacco Control Program, BC Ministry of Health.

Moore, L., Roberts, C., \& Tudor-Smith, C. (2001). School smoking policies and smoking prevalence among adolescents: Multilevel analysis of cross-sectional data from wales. Tobacco Control, 10, 117-123.

Murnaghan, D. A., Leatherdale, S. T., Sihvonen, M., \& Kekki, P. (2008). A multilevel analysis examining the association between school-based smoking policies, prevention programs and youth smoking behavior: Evaluating a provincial tobacco control strategy. Health Education Research, 23, 1016-1028.

Murnaghan, D. A., Sihvonen, M., Leatherdale, S. T., \& Kekki, P. (2007). The relationship between school-based smoking policies and prevention programs on smoking behavior among grade 12 students in Prince Edward Island: A multilevel analysis. Preventive Medicine, 44, 317-322.

Murray, D. M., Alfano, C. M., Zbikowski, S. M., Padgett, L. S., Robinson, L. A., \& Klesges, R. (2002). Intraclass correlation among measures related to cigarette use by adolescents: Estimates from an urban and largely African American cohort. Addictive Behaviors, 27, 509-527.

Northrup, D. A., Ashley, M. J., \& Ferrence, R. (1998). The Ontario ban on smoking on school property: Perceived impact on smoking. Canadian Journal of Public Health, 89, 224-228.

Otten, R., Engels, R. C., \& Prinstein, M. J. (2009). A prospective study of perception in adolescent smoking. Journal of Adolescent Health, 44, 478-484.

Pentz, M. A., Sussman, S., \& Newman, T. (1997). The conflict between least harm and no-use tobacco policy for youth: Ethical and policy implications. Addiction, 92, 1165-1173.

Perry, C. L., Williams, C. L., Komro, K. A., Veblen-Mortenson, S., Stigler, M. H., Munson, K. A., et al. (2002). Project Northland: Long-term outcomes of community action to reduce adolescent alcohol use. Health Education Research, 17, 117-132.

Perry, C. L., Williams, C. L., Veblen-Mortenson, S., Toomey, T. L., Komro, K. A., Anstine, P. S., et al. (1996). Project Northland: Outcomes of a communitywide alcohol use prevention program during early adolescence. American Journal of Public Health, $86,956-965$.

Petraitis, J., Flay, B. R., \& Miller, T. Q. (1995). Reviewing theories of adolescent substance use: Organizing pieces in the puzzle. Psychological Bulletin, 117, 67-86.

Pierce, J. P., Distefan, J. M., Kaplan, R. M., \& Gilpin, E. A. (2005). The role of curiosity in smoking initiation. Addictive Behaviors, 30, 685-696.

Pinilla, J., Gonzalez, B., Barber, P., \& Santana, Y. (2002). Smoking in young adolescents: An approach with multilevel discrete choice 
models. Journal of Epidemiology and Community Health, 56, 227-232.

Poulin, C. C. (2007). School smoking bans: Do they help/do they harm? Drug \& Alcohol Review, 26, 615-624.

Poulsen, L. H., Osler, M., Roberts, C., Due, P., Damsgaard, M. T., \& Holstein, B. E. (2002). Exposure to teachers smoking and adolescent smoking behaviour: Analysis of cross sectional data from Denmark. Tobacco Control, 11, 246-251.

Rasmussen, M., Damsgaard, M. T., Holstein, B. E., Poulsen, L. H., \& Due, P. (2005). School connectedness and daily smoking among boys and girls: The influence of parental smoking norms. European Journal of Public Health, 15, 607-612.

Reid, J. L., Manske, S. R., \& Leatherdale, S. T. (2008). Factors related to adolescents' estimation of peer smoking prevalence. Health Education Research, 23, 81-93.

Reitsma, A. H., \& Manske, S. (2004). Smoking in Ontario schools: Does policy make a difference? Canadian Journal of Public Health, 95, 214-218.

Schnohr, C. W., Kreiner, S., Rasmussen, M., Due, P., Currie, C., \& Diderichsen, F. (2008). The role of national policies intended to regulate adolescent smoking in explaining the prevalence of daily smoking: A study of adolescents from 27 European countries. Addiction, 103, 824-831.

Snijders, T., \& Bosker, R. (1999). Multilevel analysis: An introduction to basic and advanced multilevel modeling. London: Sage.

Stephens, Y. D., \& English, G. (2002). A statewide school tobacco policy review: Process, results, and implications. Journal of School Health, 72, 334-338.

Sussman, S. (1989). Two social influence perspectives of tobacco use development and prevention. Health Education Research, 4, 213-223.

Trinidad, D. R., Gilpin, E. A., \& Pierce, J. P. (2005). Compliance and support for smoke-free school policies. Health Education Research, 20, 466-475.

Urberg, K. A., Degirmencioglu, S. M., \& Pilgrim, C. (1997). Close friend and group influence on adolescent cigarette smoking and alcohol use. Developmental Psychology, 33, 834-844.

Wakefield, M. A., Chaloupka, F. J., Kaufman, N. J., Orleans, C. T., Barker, D. C., \& Ruel, E. E. (2000). Effect of restrictions on smoking at home, at school, and in public places on teenage smoking: Cross sectional study. British Medical Journal, 321, 333-337.

Willemsen, M. C., \& De Zwart, W. M. (1999). The effectiveness of policy and health education strategies for reducing adolescent smoking: A review of the evidence. Journal of Adolescence, 22, 587-599.

World Health Organization. (2006). The facts about smoking and health. Retrieved May 15, 2009, from http://www.wpro.who. int/media_centre/fact_sheets/fs_20060530.htm.

\section{Author Biographies}

Catherine Sabiston is an Assistant Professor in the Department of Kinesiology and Physical Education at McGill University. Her research focus is on understanding psychosocial correlates of multiple youth health behaviors, including tobacco use, diet, and physical activity.
Chris Lovato is an Associate Professor in the School of Population and Public Health and Director of the Evaluation Studies Unit in the Faculty of Medicine at the University of British Columbia. Her research in public health focuses on evaluation of health interventions, with a particular emphasis on adolescent tobacco control.

Rashid Ahmed is a Statistician with the Population Health Research Group and a Ph.D. candidate in Bio-Statistics at the University of Waterloo. His research focuses on longitudinal data analysis with particular emphasis on missing data and sampling design. His research focuses on school based evaluation with particular emphasis on youth behaviour.

Allison Pullman is a Research Coordinator in the School of Population and Public Health at the University of British Columbia. Her research interest is in chronic disease prevention and health promotion.

Valerie Hadd is a Ph.D. candidate in the School of Human Kinetics at the University of British Columbia. Her research in exercise and health psychology examines the role of physical activity on stressrelated variables in healthy and special populations.

Sharon Campbell is a Scientist at the Centre for Behavioural Research and Program Evaluation (CBRPE), a Canadian collaborative enterprise funded by the Canadian Cancer Society and located at the University of Waterloo. With more than 15 years of research experience, Sharon provides scientific expertise to the Centre to help integrate research and evaluation with policies and programs to accelerate improvements in the health of the population. Her area of specialization is supportive care-focused on peer support, cancer information services, caregiver needs and the unmet needs of cancer survivors-and evaluation of the reach, utilization and effectiveness of tobacco quitlines in Canada.

Candace Nykiforuk is an Assistant Professor with the Centre for Health Promotion Studies in the School of Public Health at the University of Alberta. Her research in chronic disease prevention focuses on the relationships between health and place, with a particular emphasis on policy interventions.

K. Stephen Brown is a Professor in the Department of Statistics and Actuarial Science at the University of Waterloo where he is also CoDirector of the Population Health Research Group. He is interested in the development and application of statistical methods for data arising from interventions in the health sciences, particularly in the area of tobacco control. 